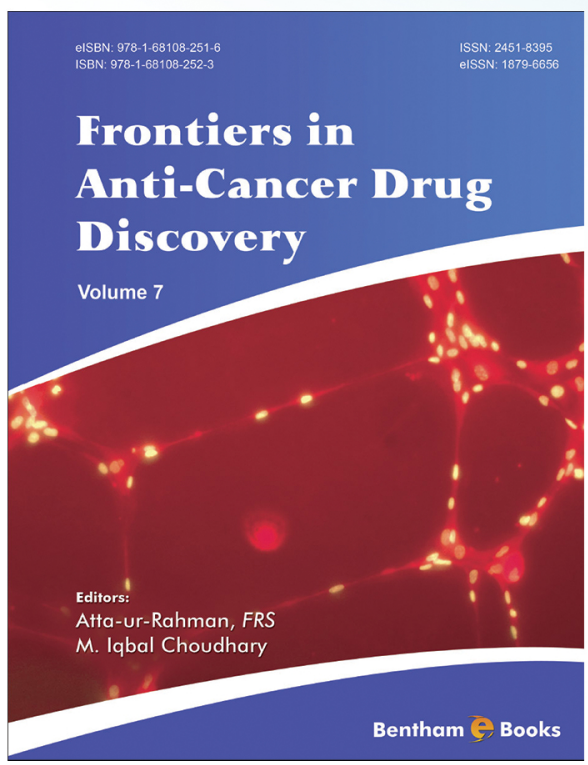

Editors:

\title{
E-book Price
}

US\$ 129.00

Print-on-Demand

US\$ 155.00

Atta-ur-Rahman

Prof. M. Iqbal Choudhary

eISBN: $978-1-68108-251-6$

\section{US\$ 516.00}

\section{Frontiers in Anti-Cancer Drug Discovery [Volume 7]}

\section{WWW.ehooks.henthamseienee.Com/hook/9781681082516/}

\section{About the eBook}

Frontiers in Anti-Cancer Drug Discovery" is an eBook series devoted to publishing the latest and the most important advances in Anti-Cancer drug design and discovery. Eminent scientists write contributions on all areas of rational drug design and drug discovery including medicinal chemistry, in-silico drug design, combinatorial chemistry, high-throughput screening, drug targets, recent important patents, and structure-activity relationships. The eBook series should prove to be of interest to all pharmaceutical scientists involved in research in Anti-Cancer drug design and discovery. Each volume is devoted to the major advances in Anti-Cancer drug design and discovery. The eBook series is essential reading to all scientists involved in drug design and discovery who wish to keep abreast of rapid and important developments in the field

\section{Contents}

- Malignant Pleural Mesothelioma (MPM): Latent Disease

- Colorectal Cancer Therapeutic Approaches: From Classical Drugs to New Nanoparticles

- The Latest Developments in Anti-Pancreatic Cancer Drugs: A Promising Future Ahead

- Adjuvant Endocrine Therapy for Early Breast Cancer

- Cyclin E and its Potential Use for Liver Cancer Prognosis and Therapy

\section{For Advertising Inquiries: Contact: marketing@benthamscience.org}

